\title{
Stabilization of Inter-Area Oscillations in a Two- Area Test System via Interval Type-2 Fuzzy Based Dynamic Brake Control
}

\author{
Mohamed Fayez Ahmed ${ }^{1 *}$, Mohamed Adel Mandor ${ }^{2}$, Mohamed El-Hadidy $^{3}$ and Fahmy Bendary ${ }^{4}$ \\ ${ }^{1}$ Faculty Cairo Electricity Production Company, Cairo, Egypt. \\ ${ }^{2,4}$ Faculty of Engineering, The University of Benha, Cairo, Egypt. \\ ${ }^{3}$ Egyptian Electricity Holding Company, Cairo, Egypt. \\ *Corresponding author: eng_mf69@yahoo.com, Tel: +2001063221535
}

\begin{abstract}
Inter-area oscillations are, by far, the most detrimental to the synchronous integrity of interconnected power systems. This detriment comes from their wide frequency spectrum and the large numbers of the participant generators. The inherent poor damping associated with the inter-area oscillations leaves open wide probabilities for irrevocable widespread blackouts with the consequent eventual devastating outcomes measured in terms of the huge economic casualties and the possible human fatalities. This article explores the influences of the Interval Type-2 fuzzy logic-based strategized dynamic braking interventions of dual brake models, namely Thyristor Controlled Braking Resistors (TCBRs), for neutralizing the jeopardy of

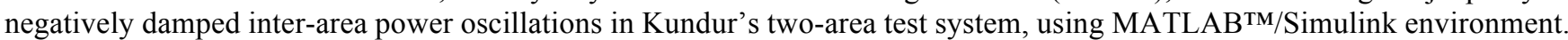
The relative inner generator's speed deviation is employed in this work as a control signal to the proposed controller. The effectiveness of the proposed scheme is authenticated by considering four case studies with different severity degrees. By analyzing the performance repercussions due to four disturbances, without the implementation of the proposed scheme, the unstable nature of the system responses is clearly noticed. With the implementation of the proposed scheme, the system oscillatory behavior is stabilized in an appropriate manner. The performed comparative non-linear time-domain simulation results emphasize the great potential of the proposed scheme in mitigation of inter-area power oscillations according to the considered disturbances. The proposed scheme is simple yet effective in treating the inter-area oscillations appropriately under the considered case studies.
\end{abstract}

Keywords: Thyristor controlled braking resistor, Fuzzy logic control, Interval Type-2 Fuzzy logic control, Inter-area oscillations, Kundur's two-area test system.

Article History: received 20 March 2020; accepted 15 April 2020; published 25 April 2020.

(C) 2020 Penerbit UTM Press. All rights reserved

\section{INTRODUCTION}

Electric power system has been experiencing the oscillatory (swing) behavior from its very beginning [1]. This oscillatory swing behavior is inherent, frequent, and overwhelmingly occurring due to anonymous stimulation mechanisms from the standpoint of many transmission system operators (TSOs) [2]. Power system oscillations can be categorized by their interaction characteristics as high-frequency torsional modes of oscillations, control modes of oscillations, local plant modes of oscillations, and inter-area modes of oscillations [2]. Although all of these categories are very much related and might be very likely to occur at the same time in the same power system [2], this work's main focus is on inter-area oscillations. Among the multiple presently conceivable categories of power system oscillations, inter-area oscillations are, by far, the most detrimental to the synchronous integrity of interconnected power systems [1]. This detriment comes from their wide frequency spectrum and the large numbers of the participant generators and the inherent poor damping associated with these oscillations [1, 2]. Inter-area oscillations are associated with a combination of closely coupled generators in a power system swinging with respect to another combination of closely coupled generators in another power system interconnected via electrically weak transmission interface with a frequency range from $0.1 \mathrm{~Hz}$ to $1 \mathrm{~Hz}$ [2]. The presence of poorly damped inter-area oscillations imposes limits on the power transfer capacity of a transmission corridor and jeopardizes the intact operation of interconnected power systems by being one of the main reasons behind many worldwide blackouts [3-5]. Poorly damped inter-area oscillations are identified as posing a serious potential hazard to the generation establishments and the transmission facilities [5]. Obviously, under the poorly damped inter-area oscillatory behavior, the protection system, the primary sentinel of the grid, responds to these oscillations by taking tripping actions to the different system elements causing cascading element outages which is known as the domino effect in the grid.

The inherent poor damping associated with the inter- 
area oscillations leaves open wide probabilities for irrevocable widespread blackouts with the consequent eventual devastating outcomes measured in terms of the huge economic casualties and the possible human fatalities $[2,5,6]$. Due to the unceasing industry's quest to a deregulated platform transition, and the lack of transmission expansion projects, many transmission links are becoming more prone to be convoying heavier electric power transfers often close to the safe maximum loading limit $[2,7,8]$. Exploiting the transfer capability of transmission links that much deteriorates the damping of inter-area oscillation very seriously $[2,7,8]$. This situation makes the interconnected power systems more vulnerable to suffer from the weakly damped inter-area oscillations and the increased probabilities of system separations (islanding) $[2,7,8]$. Therefore, the main purpose of this work is to mitigate inter-area power oscillations developed due to the different grid perturbations.

One of the several mitigation approaches that have been developed for mitigation of inter-area oscillations is the utilization dynamic braking resistor [8, 9]. Dynamic braking resistor is one of the multiple prospective mitigation candidates [10]. In Fact, the European Network of Transmission System Operators-for-ElectricityContinental Europe Synchronous Area (ENTSO-ECESA), Working Committee gave a recommendation to the Turkish decision makers to install number of Braking Resistors as precautionary countermeasure in anticipation of the weakly damped $0.15 \mathrm{~Hz}$ inter-area oscillation mode [10]. This mode was a collateral result for the synchronous interconnection between the Turkish grid and the ENTSOE-CESA in 2009 and manifested under stressed operating conditions [10]. Dynamic braking resistor controlled via high-power thyristors is considered a special purpose, and cost-effective FACTS controller employed for mitigation of multi-modal torsional oscillations, damping subsynchronous resonance (SSR) oscillations, and augmenting the power system transient stability [11]. The conceptual principal of the dynamic braking resistor is to energize an extra pseudo load to dissipate any excess energy developed due to system perturbations and deenergize it elsewhere [11]. Bonneville Power Administration (BPA) has developed one of the largest existing Dynamic braking resistor installations in realistic power systems rated $1400 \mathrm{MW}$ and $230 \mathrm{kV}$ [12].

The mitigation scheme proposed herein builds on the findings presented in [13]. In [13], the authors introduced single TCBR unit for stabilizing the inter-area oscillations in Kundur's two-area test system and the TCBR energization signal was the speed of equivalent onemachine infinite bus (OMIB) without considering any Artificial Intelligence (AI) based controller. Moreover, in [13], the authors introduced the OMIB response to demonstrate the effectiveness of their scheme. This article explores the influences of the Interval Type-2 fuzzy logicbased strategized dynamic braking interventions of dual brake models, namely Thyristor Controlled Braking Resistors (TCBRs), for neutralizing the jeopardy of negatively damped inter-area power oscillations in Kundur's two-area test system, using MATLAB ${ }^{\mathrm{TM}} /$ Simulink environment with the help of
Interval Type-2 Fuzzy Logic Controller (IT2FLC) tool box. The relative inner generator's speed deviation is employed in this work as a control signal to the proposed controllers. There is no such similar work in the literature with regard to the implementation of dual Interval Type-2 fuzzy controlled TCBRs for mitigation inter-area oscillations. This study will introduce the responses of inter-area active and reactive power beside the inner and the outer generator's relative speeds to demonstrate the mitigation capability of the proposed scheme. The rest of this article is organized as follows. In section 2 , a summarized description of the test system is presented. In section 3 , the idea of utilizing the IT2FLC to coordinate the dynamic braking interventions of the dual TCBRs is introduced. In section 4, MATLAB ${ }^{\mathrm{TM}} /$ Simulink comparative time domain simulation results are depicted with comments. In section 5, the key findings are concluded. Finally, the list of references used in this work is presented.

\section{SYSTEM MODEL}

In this article, the well-known Kundur two-area benchmark test system is considered to demonstrate the soundness of the proposed scheme. It is basically a fourmachine two-area interconnected power system [9]. The single-line diagram of the test system is shown in Fig.1 [9]. It is a hypothesis-based power system with genuine parameters and it is overwhelmingly employed for studying inter-area oscillations by many researchers [9]. This benchmark was constructed by Ontario Hydro for a research report commissioned by the Canadian Electrical Association (CEA) to study the inter-area oscillations phenomenon [9]. It consists two virtually identical areas (active networks) interconnected by two $220 \mathrm{~km} 230 \mathrm{kV}$ interconnecting tie-lines [9]. The considered transmission corridor is relatively weak especially with bulk power interchange between the two areas [9]. Each area contains two round rotor $(60 \mathrm{~Hz})$ synchronous generators rated 20 $\mathrm{kV} / 900 \mathrm{MVA}$ and the only parameters discrepancy is the inertia constant $(\mathrm{H})$ which equals 6.5 seconds for each machine in area 1 , and 6.175 seconds for each machine in area 2, respectively [9]. A steam turbine is supposed to be the prime mover for all generators in the test system. For the sake of succinctness, the parameters and the dynamic data for the test system are easily obtained from [9]. The considered distribution of generated powers and loads causes a power interchange of $413 \mathrm{MW}$, as similar to the work found in [9], to be transferred from area 1 to area 2, as denoted from the direction of the arrow in Figure 1. This condition is considered in all case studies.

There are two $30 \mathrm{MW}$ TCBR which are installed at both ends of the transmission corridor, i.e. at bus 7 and at bus 8 , as depicted in Figure 1. Each TCBR is controlled by a separately dedicated IT2FLC to strategize the interventions of the dynamic braking resistor. Detail depictions of each TCBR are shown in Figure 2. In this paper, the relative kinetic energy deviation between the two areas are utilized as an input signal to each IT2FLC. 


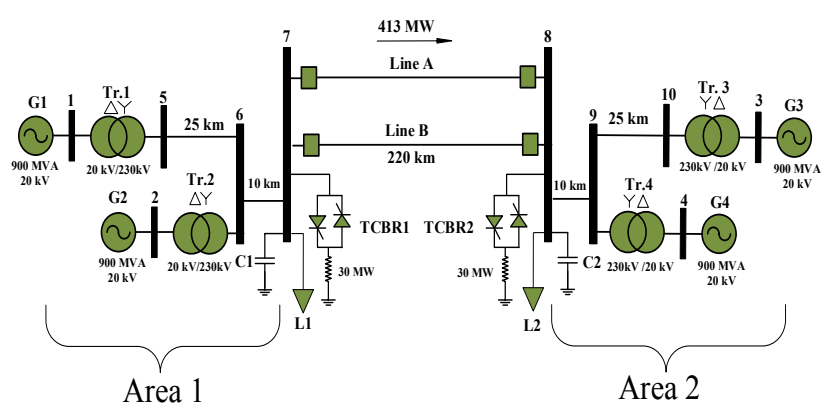

Figure 1. Single- line diagram of four-machine two-area test power system with dual $30 \mathrm{MW}$ TCBRs

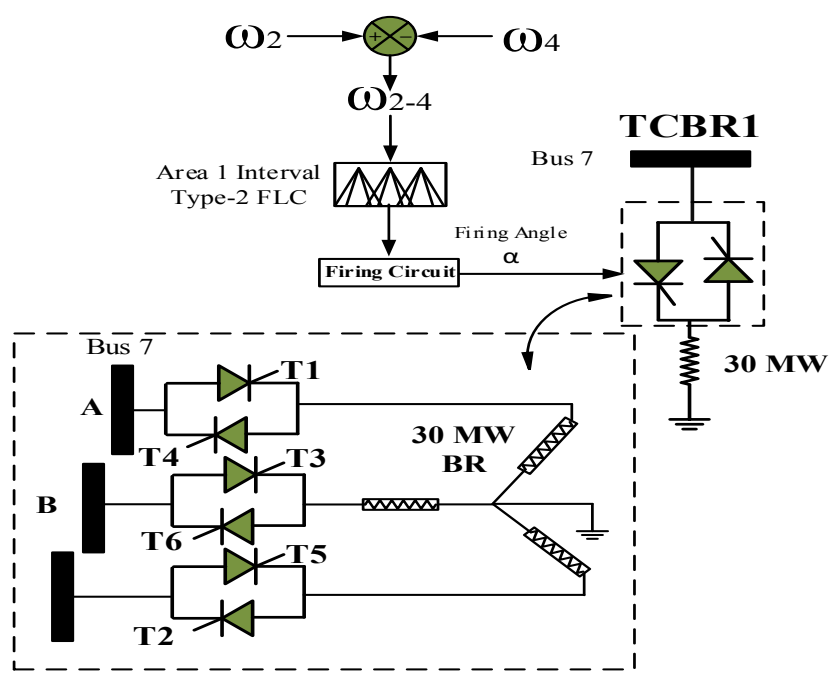

(a)

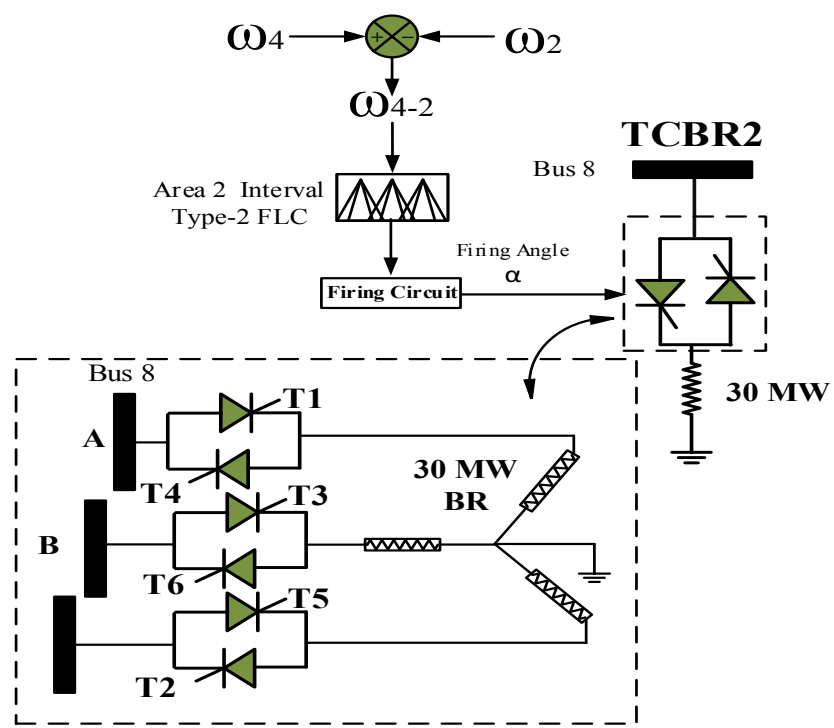

(b)

Figure 2. Details for each of the dual TCBRs with the IT2FLC and the input control signal, (a) Detail of area 1 single-line diagram of TCBR installed at bus 7, (b) Detail of area 2 single-line diagram of TCBR installed at bus 8

The considered TCBR model is simply a 3-phase, bidirectional, full wave phase-controlled $\mathrm{AC} / \mathrm{AC}$ converter through which a $30 \mathrm{MW}$ three-phase Y-connected linear resistor bank. It is built in MATLAB ${ }^{\mathrm{TM}} /$ Simulink environment by utilizing three antiparallel pairs of highpower thyristors to compose three-phase ac voltage controller which is linked to the high voltage busses number 7 and 8 as shown schematically in Figure 2.

The proposed strategy in this paper relied on the hypothetical post-existence of the communication infrastructure needed for the control signal acquisition and transmission from the different power plants in the test system to the IT2FLC dedicated for each area. The power system simulation is implemented in SimPower ${ }^{\circledR}$ of MATLAB $^{\text {TM}} /$ Simulink which is possible to find the complete system as a demo. Extensive non-linear time domain simulations are performed to highlight the capability of TCBRs to effectively mitigate inter-area power oscillations through ON-OFF (bang-bang) Interval Type-2 fuzzy-based control.

\section{INTERVAL TYPE-2 FUZZY LOGIC CONTROLLER DESIGN}

It is widely-confirmed that conventional linear-based controllers, such as PI and PID controllers, are not able to perform effectively when controlling systems to be with high degrees of nonlinearities and uncertainties [14]. Moreover, changing the system parameters would much more likely cause dire consequences on the stability of the controlled system [14]. Subsequently, nonlinear intelligent controllers such as fuzzy logic controllers have been exceedingly employed for controlling nonlinear systems because they are much more robust than linear controllers and are able to handle system parameters changes in an appropriate manner [14].

Fuzzy logic controllers could be categorized to two main categories, Type-1 fuzzy logic controllers and Type2 fuzzy [15]. The vast majority of the fuzzy logic controllers that have been used to date belongs to Type-1 category [15]. Type-2 fuzzy logic controllers introduce far superior performance over Type-1 fuzzy logic controllers due to their great capability of handling uncertainties [15]. Therefore Type-2 fuzzy logic controller is suggested in this article due to its great capability of handling uncertainties. Type-2 fuzzy logic could be considered the state-of-the art in the fuzzy logic scope in which the uncertainty is not only limited to the linguistic variables but also is concerned with the membership function themselves [16]. Type-2 fuzzy logic is conceptually based on Type-2 fuzzy sets theorem which was primarily proposed to the academic peer society by Zadeh back in the seventies [16]. Very recently, Type-2 fuzzy logic has acquired so much reputability inside the peer community in engineering applications due to its great capability of accommodating higher levels of uncertainties involved in the system's parameters [17]. Type-2 fuzzy logic is now broadly received a considerably escalating attention with very promising potentials in scopes such as modelling, pattern recognition, classification and control [17]. Type-2 fuzzy logic controller becomes a preferential option for many academic researchers when there are facing control situations characterized by the hardness of determining the suitable membership function for a fuzzy set [17].

Type-2 fuzzy logic controllers have been employed for treating many power system dynamic problems as a far superior alternative to Type-1 fuzzy logic controllers [17$22]$. In $[17,19,20,22]$, Type-2 fuzzy logic controllers are 
implemented to design power system stabilizers for damping power system oscillations. In [18], Type-2 fuzzy logic controller is employed to control a ThyristorControlled Series Capacitor (TCSC) device to provide supplementary damping action to the low-frequency power system oscillations. In [21], Type-2 fuzzy logic controller is used to design a control strategy for the purpose of integrating the doubly fed induction generator (DFIG) based wind turbines to the distribution grid.

The main components of A generic type-2 fuzzy logic controller is composed of five main components a Fuzzifier, a Rule-Base, an Inference Engine, a TypeReducer, and a Defuzzifier [16]. The structural block diagram of a Type-2 fuzzy logic controller is depicted in Figure 3 [16].

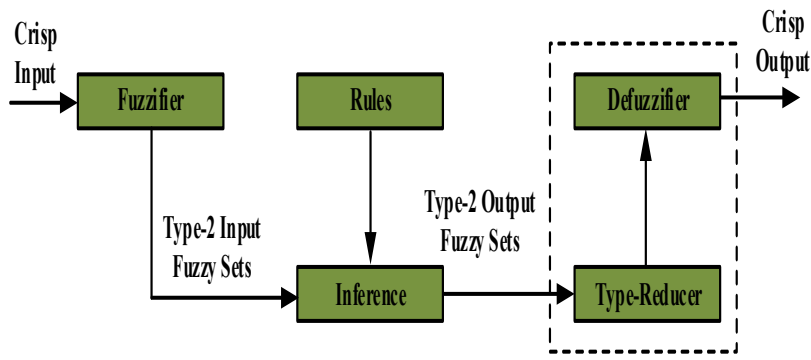

Figure 3. General structure of Type-2 fuzzy logic controller

Many academic researchers have been devoting much of their attention on a less complicated version of Type- 2 fuzzy logic controller known as Interval Type-2 fuzzy logic controller [22]. The degree of membership for each element of the fuzzified input in Interval Type-2 FLC is itself an interval-valued fuzzy set, unlike a Type-1 FLC in which the degree of membership is a crisp value lying between one and zero [23]. So, Interval Type-2 FLC will be implemented in this article. The suggested controller is designed with the assist of Interval Type-2 FLC tool box [23].

The fuzzy inference type utilized in this work is of Takagi-Sugeno-Kang (TSK) type. The fuzzy rule consequent in TSK inference system is constant (i.e. zeroorder type-2 Sugeno model) which eliminates the need for type reduction and defuzzification in the proposed controller and thus much of the computational burden is relieved [23].

Interval Type-2 gaussian and sigmoid membership functions are chosen to represent the input control variable of the Interval Type- 2 FLC (i.e. $\omega_{2}-\omega_{4}$ and/or $\omega_{4}-\omega_{2}$ in p.u.). The input membership functions for both of the proposed controllers are depicted in Figure 4 in which only three linguistic variables, namely, NB (Negative Big), Z (Zero), and PB (Positive Big), are realizing the fuzziness of the controller input. The parameters of the membership functions are constant throughout the simulation study for all case studies and determined by trial and error approach. The output is constant having either 0 or 1 values $(0$ for both $\mathrm{Z}$ and NE, 1 for PB). Where 0 implies that the TCBR should be fully OFF and 1 indicates that the TCBR should be fully $\mathrm{ON}$.

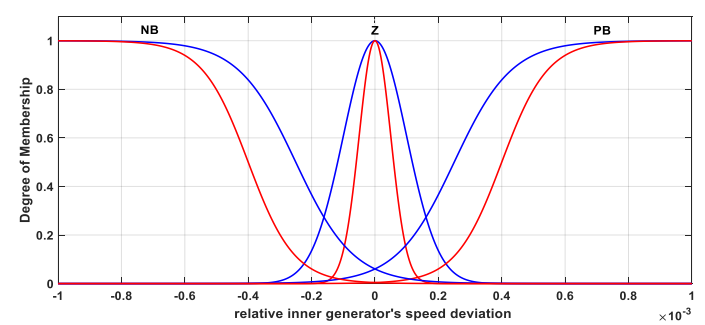

Figure 4. Membership function of relative inner generator's speed deviation in [p.u]

The suggested Interval Type-2 fuzzy-based control scheme is straightforward because it contains only three control rules where the TCBR is energized if the control signal exceeds a certain value. There are three premise membership functions and single input in Figure 4 result in three control rules. The fuzzy control rules harnessed in the rule base of the proposed scheme are as follows: IF the input is NB THEN the output is 0 , IF the input is $Z$ THEN the output is 0 , and IF the input is PB THEN the output is 1. The output signal of Interval Type-2 FLC is then sent to the thyristor gating circuitry which generates the firing signals for the thyristor valves based on the controller decision.

\section{SIMULATION RESULTS}

To demonstrate the effectiveness of the proposed dynamic braking scheme comparative time-domain approach based on a non-linear system model via MATLAB ${ }^{\mathrm{TM}} /$ Simulink platform are carried out in this section. Four case studies with different severity degrees are performed. The responses of intertie active power flow and reactive power flow transported from area 1 to area 2 are examined with and without the proposed scheme for each case study to authenticate the effectiveness of the proposed scheme.

\subsection{Case Study (1) - Small Step Change in the Reference Voltage Set Point of Machine (1)}

Under the considered stressed operating conditions, the benchmark system is triggered to experience the inter-area oscillations by having a small step-change increase of 0.05 p.u. in the reference voltage set point of machine number 1 from 0.5 to 0.7 second of the simulation time of 10 seconds. The corresponding intertie active power and reactive power flow responses as measured at the beginning of bus 7 with and without the Interval Type- 2 fuzzy-based dynamic braking interventions are depicted in Figure 5 .

Without the proposed scheme, the unstable nature of the inter-area oscillations can be obviously noticed from the outline of Figure 5. The amplitudes of the power swing traces are periodically increasing as the simulation time proceeds. The protection system shall respond to these unstable oscillations by taking tripping actions to the power system elements and then inevitably, whole power system will be destined to fall apart. With the implementation of the proposed scheme, the power swing traces are stabilized in an appropriate manner. The unstable nature of the inter-area mode of oscillation can be also noticed in the responses of the relative generator speeds $\left(\omega_{1-} \omega_{3}\right.$ and $\omega_{2} \omega_{4}$ in p.u. $\omega_{1}-\omega_{3}$ and $\omega_{2}-\omega_{4}$ in 
p.u.). Figure 6 illustrates responses of the relative generator speeds due to the experienced small disturbance.

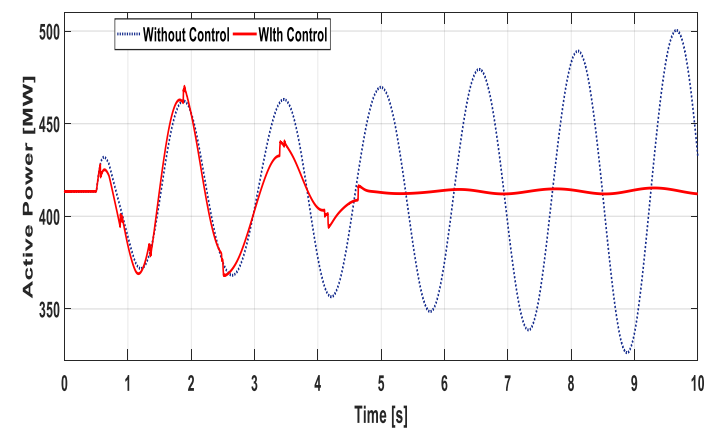

(a)

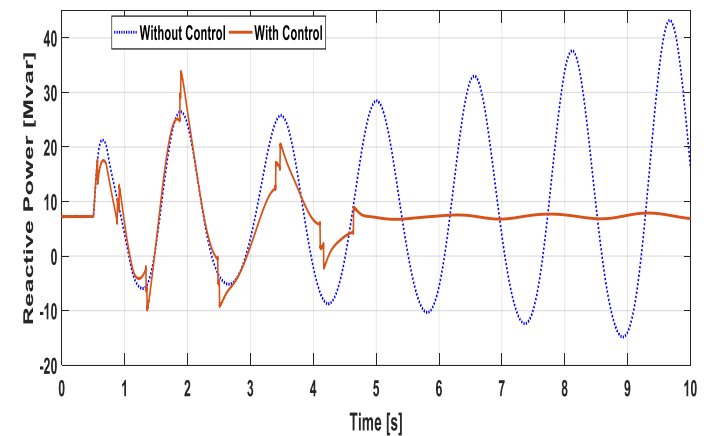

(b)

Figure 5. Power flow responses to the small disturbance with and without the dynamic braking interventions, (a)

Inter-area active power flow, (b) Inter-area reactive power flow

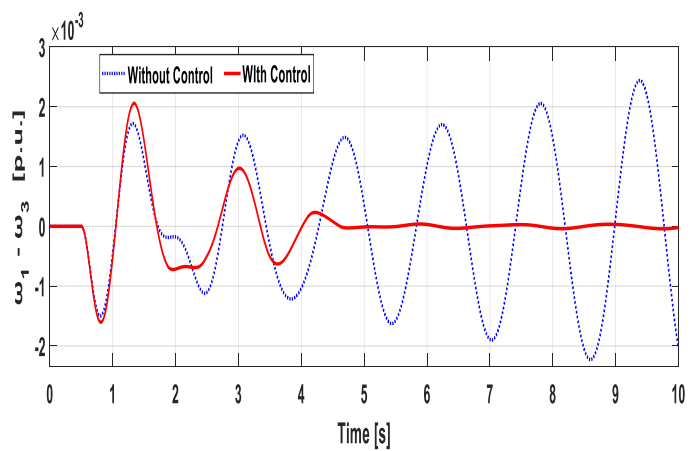

(a)

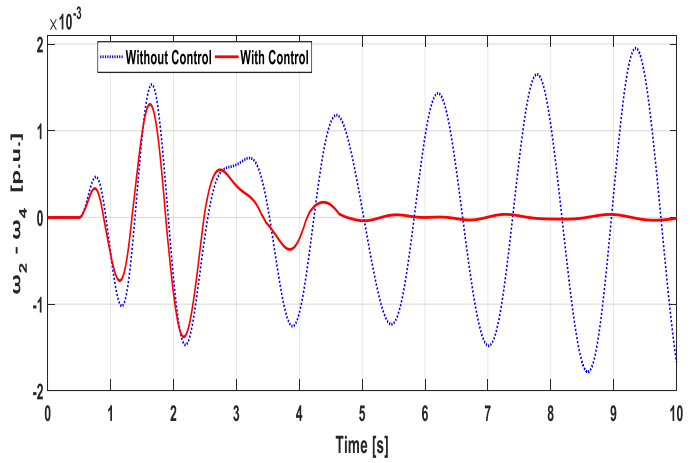

(b)

Figure 6. Relative generator speeds due the small disturbance with and without the proposed scheme, (a) a

$$
\omega_{1}-\omega_{3} \text { in [p.u.], (b) } \omega_{2}-\omega_{4} \text { in [p.u.] }
$$

As can be seen from the outline of Figure 6, the unstable nature of the relative generator speeds can be obviously observed. With the implementation of the proposed scheme, the oscillations in relative generator speeds are mitigated. A simple understanding of the dynamic brake functioning could be attained by observing the behaviour of the dissipated power in each TCBR. Thus, the responses of the three-phase dissipated power in each TCBR are shown in Figure 7.

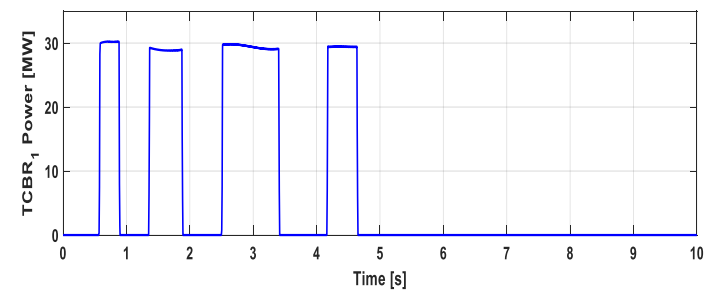

(a)

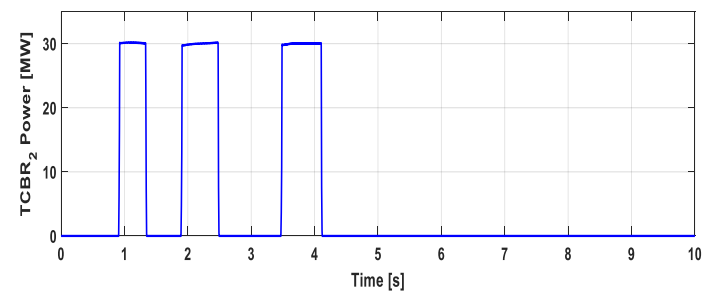

(b)

Figure 7. Dynamic braking dissipated power responses. (a) $\mathrm{TCBR}_{1}$ dissipated power, (b) $\mathrm{TCBR}_{2}$ dissipated power

\subsection{Case Study (2) - 50 MW Step-Load Increase}

The test system is stimulated to experience the inter-area oscillations by having $50 \mathrm{MW}$ step-load increase in area 2 at 0.5 second of the simulation time of 10 seconds. Figure 8 depicts the corresponding inter-area active power and reactive power flow responses as captured at bus 7 with and without the Interval Type-2 fuzzy-based dynamic braking interventions. Figure 9 illustrates responses of the relative generator speeds due to the $50 \mathrm{MW}$ load increase.

Referring to Figure 8, and Figure 9 in the base-case plot (uncontrolled plot), it is clearly noticed that the system is suffering from the unstable nature of the inter area mode of oscillation. While in the presence of the dynamic brake interventions, the system responses are stabilized appropriately. the responses of the three-phase dissipated power in each TCBR are shown in Figure 10.

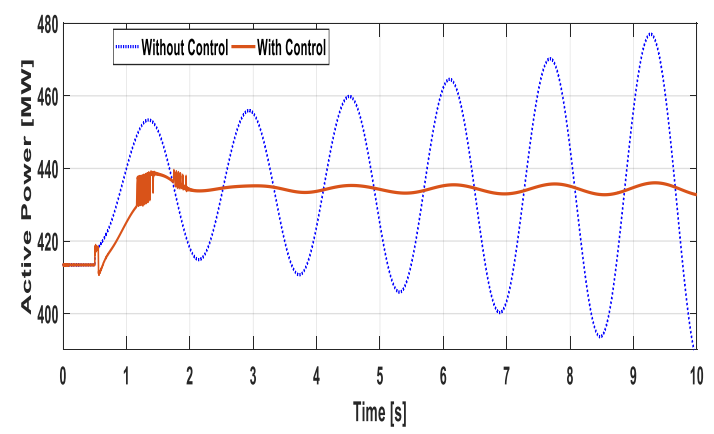

(a) 


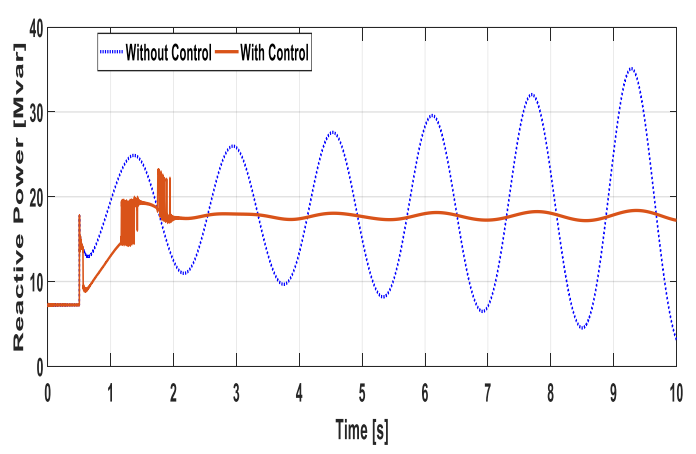

(b)

Figure 8. Power flow responses due to the $50 \mathrm{MW}$ load increase with and without dynamic brake, (a) Inter-area active power flow, (b) Inter-area reactive power flow

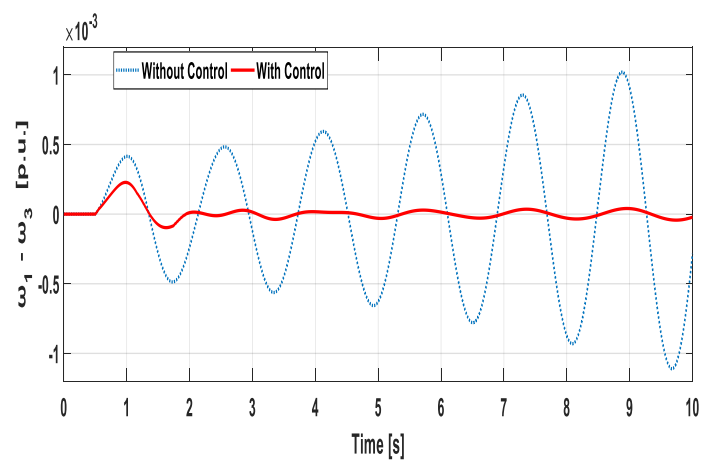

(a)

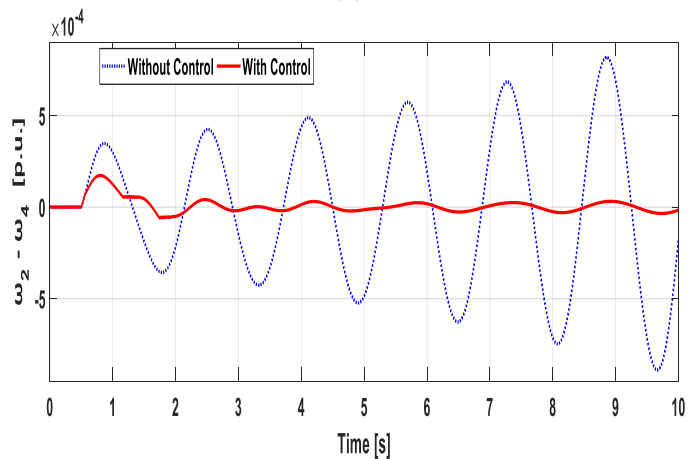

(b)

Figure 9. Relative generator speeds due the $50 \mathrm{MW}$ load increase with and without the dynamic braking interventions, (a) $\omega_{1}-\omega_{3}$ in [p.u.], (b) $\omega_{2}-\omega_{4}$ in [p.u.]

\subsection{Case Study (3) - 100 MW Sudden Load Rejection}

The test system is stimulated to experience the inter-area oscillations by having $100 \mathrm{MW}$ load sudden load rejection in area 1 at 0.5 second of the simulation time of 10 seconds. Figure 11 depicts the corresponding inter-area active power and reactive power flow responses as captured at bus 7 with and without the Interval Type-2 fuzzy-based dynamic braking interventions.

Figure 12 illustrates responses of the relative generator speeds due to the $100 \mathrm{MW}$ load sudden load rejection with and without dynamic brake.

Referring to Figure 11, and Figure 12 in the base-case plot, it is obviously seen that the system is suffering from the unstable nature of the inter area mode of oscillation. While in the presence of the dynamic brake interventions, the system responses are stabilized. the responses of the three-phase dissipated power in each TCBR are shown in Figure 13.

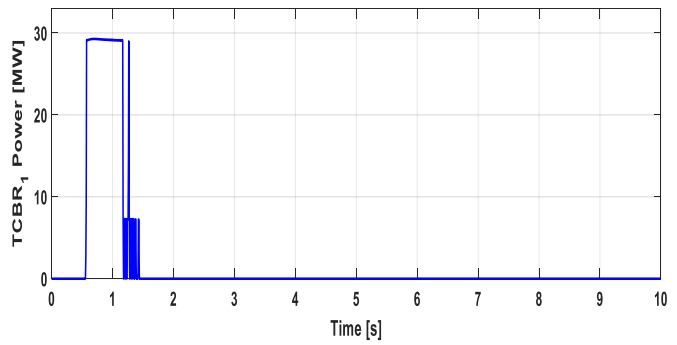

(a)

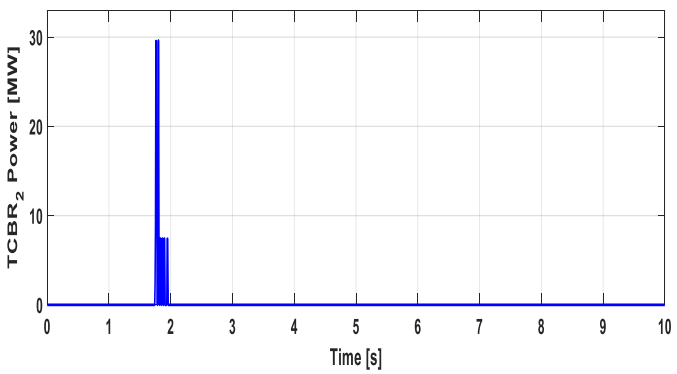

(b)

Figure 10. Dynamic braking dissipated power responses. (a) $\mathrm{TCBR}_{1}$ dissipated power, (b) $\mathrm{TCBR}_{2}$ dissipated power

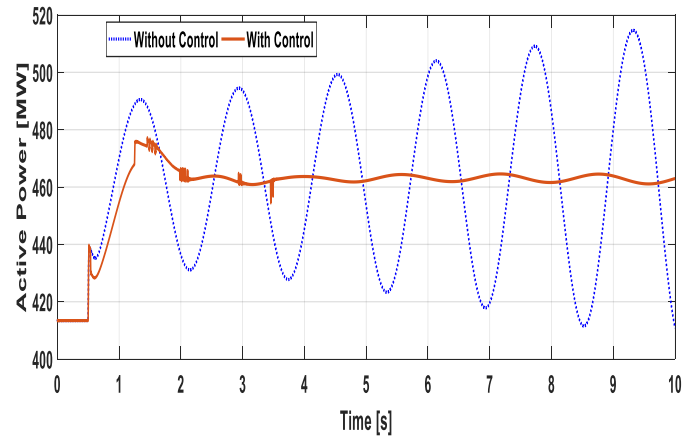

(a)

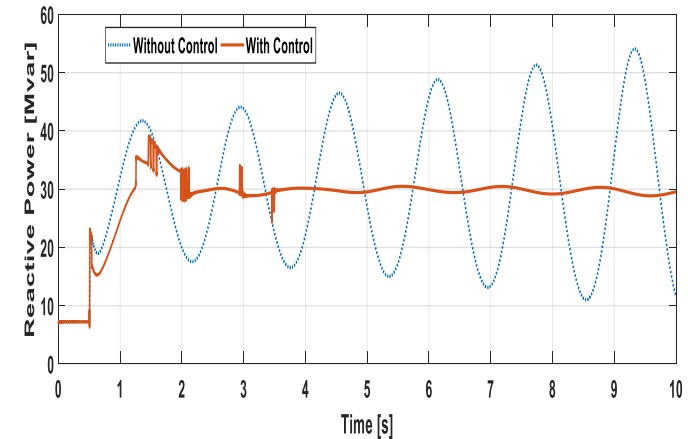

(b)

Figure 11. Power flow responses due to the $100 \mathrm{MW}$ load sudden load rejection with and without dynamic brake (a) Inter-area active power flow, (b) Inter-area reactive power flow 


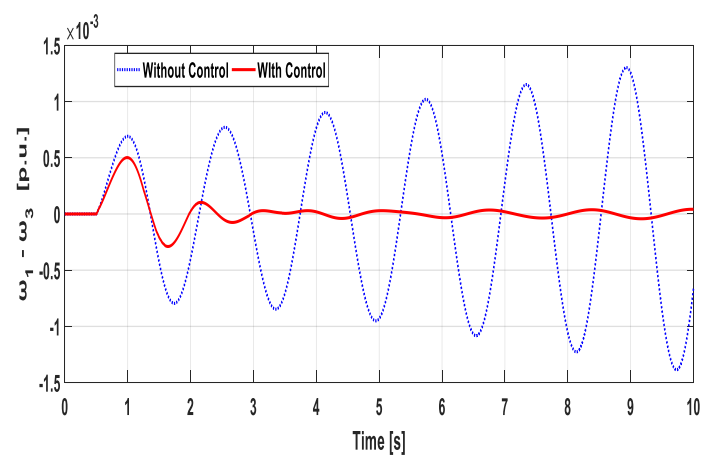

(a)

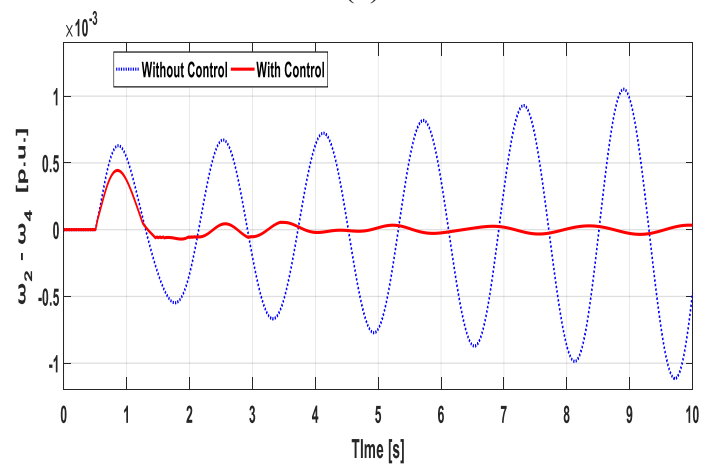

(b)

Figure 12. Relative generator speeds due the $100 \mathrm{MW}$ sudden load rejection with and without the dynamic braking interventions, (a) $\omega_{1}-\omega_{3}$ in [p.u.], (b) $\omega_{2}-\omega_{4}$ in [p.u.]

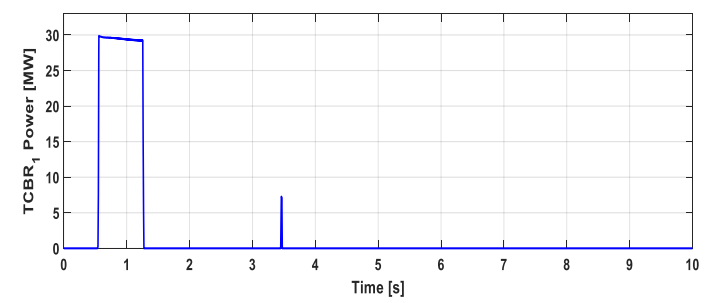

(a)

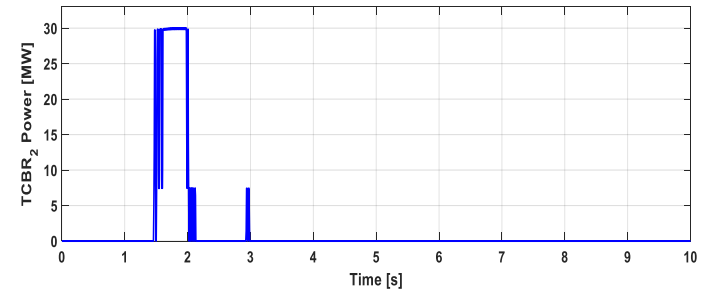

(b)

Figure 13. Dynamic braking dissipated power responses, (a) $\mathrm{TCBR}_{1}$ dissipated power, (b) $\mathrm{TCBR}_{2}$ dissipated power

\subsection{Case Study (4) - Three-Phase to Ground Fault at the Middle of Tie-Line (A)}

In this case, three-phase to ground (3LG) 1-cycle selfhealing bolted fault is applied at the middle of tie-line (A) at time $\mathrm{t}=0.5$ second. The disturbance stimulated is selfhealing fault, i.e. the involved circuit breakers are not anticipated to sever the faulted line. The two curves depicted in Figure14 highlight the comparison of the active and reactive power transfer responses of the system to this severe disturbance with and without the Interval Type- 2 fuzzy-based dynamic braking interventions.

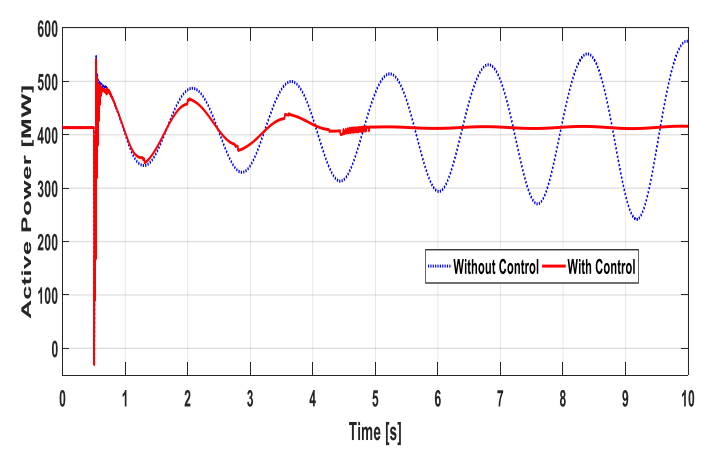

(a)

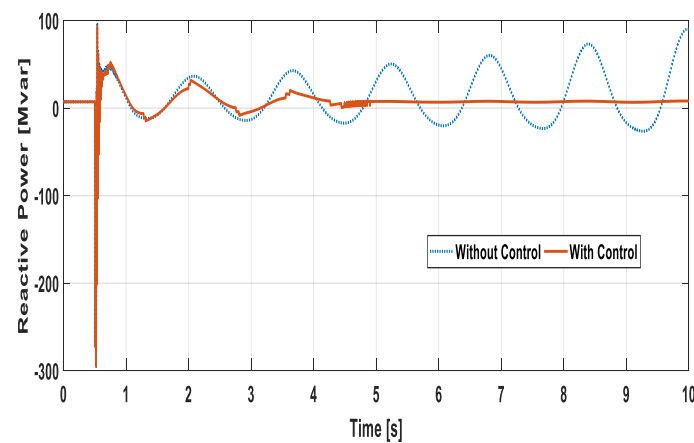

(b)

Figure 14. Power flow responses due to 1-cycle selfhealing bolted fault with and without dynamic braking interventions, (a) Inter-area active power flow, (b) Interarea reactive power flow

Figure 15 illustrates responses of the relative generator speeds due to due to three-phase to ground fault at the middle of tie-line (A) with and without dynamic brake.

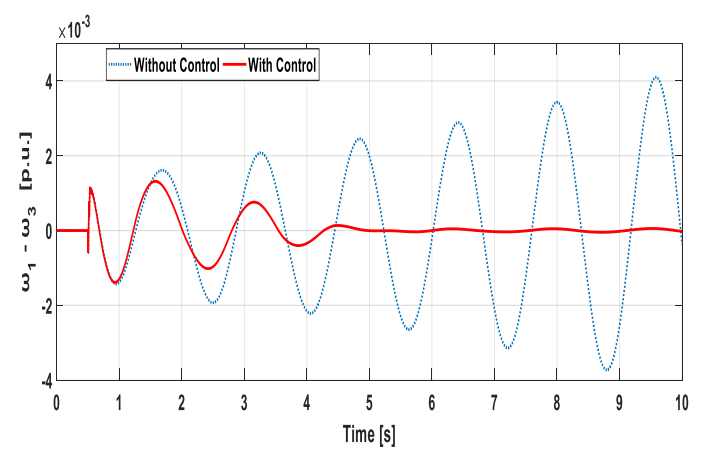

(a)

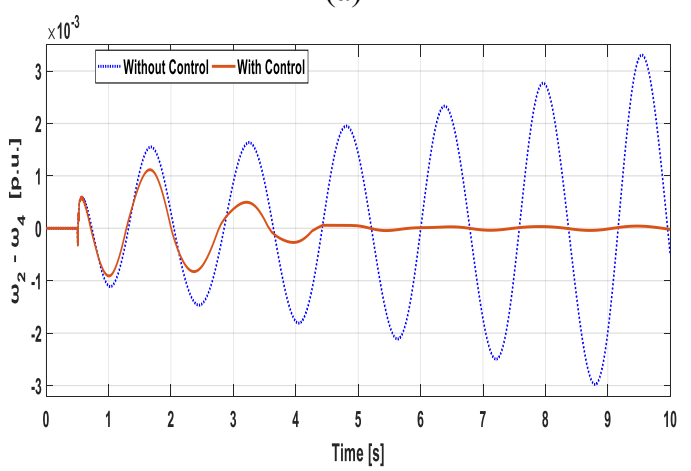

(b)

Figure 15. Relative generator speeds due to 1-cycle selfhealing bolted fault with and without the dynamic braking interventions, (a) $\omega_{1}-\omega_{3}$ in [p.u.], (b) $\omega_{2}-\omega_{4}$ in [p.u.] 
Referring to Figure 14, and Figure 15 in the base-case plot, it is obviously seen that the system is suffering unstable inter-area oscillations. While in the presence of the dynamic brake interventions, the system responses are stabilized appropriately. the responses of the three-phase dissipated power in each TCBR are shown in Figure 16.

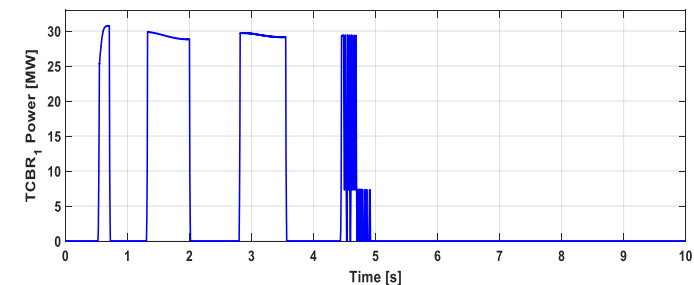

(a)

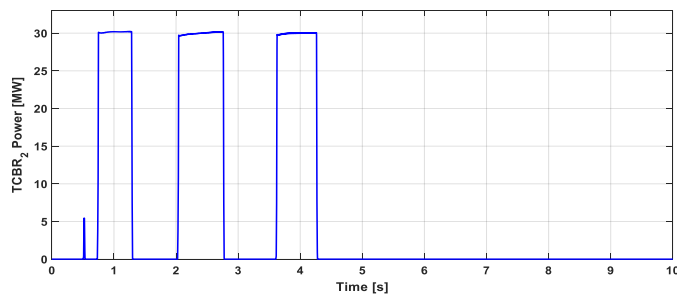

(b)

Figure 16. Dynamic braking dissipated power responses. (a) $\mathrm{TCBR}_{1}$ dissipated power, (b) $\mathrm{TCBR}_{2}$ dissipated power

\section{CONCLUSIONS}

This paper introduces an Interval Type-2 fuzzy-based switching strategy for the coordinated operation of dual TCBRs in Kundur Benchmark two-area system for the purpose of stabilization of unstable inter-area oscillations manifested due the different grid perturbations. The key finding of the article is that TCBR controlled through Interval Type-2 fuzzy-based control is simple yet effective stabilization candidate for unstable inter-area oscillations problem. Furthermore, the implementation of the proposed scheme makes the Kundur Benchmark two-area system less vulnerable to the unstable inter area oscillations with the consequent cascading element outages which are considered as the onset of irrevocable blackout events.

\section{REFERENCES}

[1] P. Ju, "Stochastic dynamics of power systems," Springer Verlag, Singapore, 2018, pp. 91-135.

[2] L. L. Grigsby, "Power system stability and control," Taylor \& Francis Inc, Bosa Roca, 2012, pp. 140-157.

[3] Cui Y, Wu L, Yu W, Liu Y, Yao W, Zhou D, Liu Y, "Inter-area oscillation statistical analysis of the U.S. eastern interconnection," The Journal of Engineering, vol. 11, pp. 595 - 605, 2017.

[4] D. P. Wadduwage, U. D. Annakkage, K. Narendra, "Identification of dominant low-frequency modes in ring-down oscillations using multiple Prony models," IET Generation, Transmission \& Distribution, vol. 15, pp. $2206-2214,2015$.

[5] S. You, G. Kou, Y. Liu, X. Zhang, Y. Cui, M. J. Till, W. Yao, Y. Liu, "Impact of high PV penetration on the inter-area oscillations in the U. S. eastern interconnection," IEEE Access, vol. 5, pp. 43614369, 2017.
[6] Z. Bo, O. Shaojie, Z. Jianhua, S. Hui, W. Geng, Z. Ming, "An analysis of previous blackouts in the world: lessons for China's power industry," Renewable and Sustainable Energy Reviews, vol. 42, pp. 1151-1163, 2015.

[7] F. K. A. Lami, "A new improved method to damp inter-area oscillations in power systems with SSR mitigation and zone protection compensation," Ph.D. Dissertation, University of Leicester, 2012.

[8] J. C. Neely, R. H. Byrne, R. T. Elliott, C. A. SilvaMonroy, D. A. Schoenwald, D. J. Trudnowski, M. K. Donnelly, "Damping of inter-area oscillations using energy storage," Proceedings of the power and energy society general meeting (PES), Vancouver, BC, Canada, pp. 1 - 5, July 21-25, 2013.

[9] M. Hadjikypris, "Supervisory control scheme for FACTS and HVDC based damping of inter-area power oscillations in hybrid AC-DC power systems," Ph.D. Dissertation, University of Manchester, 2015.

[10] S. O. B. Tor, C. Gencoglu, O. Yilmaz, E. Cebeci, A. N. Guven, "Damping Measures against Prospective Oscillations between Turkish Grid and ENTSO-E System," Proceeding of IEEE International Conference on Power System Technology (POWERCON), Hangzhou, China, pp. 1-7, October 24-28, 2010.

[11] N. G. Hingorani, L. Gyugyi, "Understanding FACTS: concepts and technology of flexible $A C$ transmission systems," I.E.E.E. Press, New York, 1999 , pp. $353-370$.

[12] M. F. Ahmed, M. A. Ebrahim, M. A. El-Hadidy, W. M. Mansour, "Torsional oscillations mitigation for interconnected power system via novel fuzzy control based braking resistor model," Presented at conseil international des grands réseaux électriques (CIGRÉ), Paris, France, pp. 1 - 9, August 26-31, 2018.

[13] E. Huseinbasic, I. Kuzle, T. Tomisa, "Inter-area oscillations damping using dynamic braking and phasor measurements," Proceedings of IEEE/PES power systems conference and exposition (PSCE), Seattle, WA, USA, pp. 1 - 6, March 15-18, 2009.

[14] G. Mosè, C. Bartolomeo, "Adaptive type-2 fuzzy control of non-linear systems," Proceedings of the IEEE International Conference on Intelligent Computing and Intelligent Systems, Shanghai, China, pp. 705 - 709, November 20-22, 2009.

[15] K. A. Naik, C. P. Gupta, "Performance comparison of Type-1 and Type-2 fuzzy logic systems," Proceedings of the 2017 4th International Conference on Signal Processing Computing and Control (ISPCC), Solan, India, pp. 72 - 76, September 21-23, 2017.

[16] R. Antão, "Type-2 fuzzy logic uncertain systems' modelling and control," Springer Verlag, Singapore, 2017

[17] M. K. Panda, G. N. Pillai, V. Kumar, "Power system stabilizer design: interval type-2 fuzzy logic controller approach," Proceedings of the international conference on power control and embedded systems, Allahabad, India, pp. 1-10, December 17-19, 2012.

[18] M. Tripathy, S. Mishra, "Interval type-2-based thyristor-controlled series capacitor to improve 
power system stability," IET Generation, Transmission \& Distribution, vol. 5, pp. 209-222, 2011.

[19] S. Kamel, B. Ziyad, H. M. Naguib, A. Mouloud, R. Mohamed, "An indirect adaptive type-2 fuzzy sliding mode PSS design to damp power system oscillations," Proceedings of International Conference on Modelling, Identification and Control (ICMIC), Sousse, Tunisia, pp. 1-6, December 18-20, 2015.

[20] K. Saoudi, Z. Bouchama, M. Ayad, M. Benziane, M. N. Harmas, "Design of a robust PSS using an indirect adaptive type-2 fuzzy sliding mode for a multimachine power system," Proceedings of international conference on modelling, identification and control, Algiers, Algeria, pp. 713-718, November 15-17, 2016.

[21] S. K. Raju, G. N. Pillai, "Design and implementation of type-2 fuzzy logic controller for DFIG-based wind energy systems in distribution networks," IEEE Transactions on Sustainable Energy, vol. 7, pp. 345353, 2016.

[22] A. Sharma, L. K. Nagar, N. P. Patidar, M. L. Kolhe, S. R. Nandanwar, V. N. Puranik, V. K. Singh, "Minimizing uncertainties with improved power system stability using wide area fuzzy-2 logic-based damping controller," Proceedings of 3rd IEEE International Conference on "Computational Intelligence and Communication Technology" (IEEE-CICT), Ghaziabad, India, pp. 1-5, February 910, 2017.

[23] O. Castillo, P. Melin, "Type-2 fuzzy logic: theory and applications," Springer-Verlag, Berlin, 2008.

[24] A. Taskin, T. Kumbasar, "An open source Matlab/Simulink toolbox for interval type-2 fuzzy logic systems," In: Proceedings of IEEE Symposium Series on Computational Intelligence, Cape Town, South Africa, pp. 1561-1568, December 7-10, 2015. 